\title{
MOVEMENT TRANSFORMATIONS IN ENGLISH SENTENCE CONSTRUCTION
}

\author{
Ruly Adha \\ IAIN Langsa \\ adharuly@yahoo.com
}

\begin{abstract}
Chomsky states that language is a mirror of the mind. From that opinion, he creates a concept which is known as competence and performance. Competence is the fluent native speaker's knowledge of his language; meanwhile, performance is what people actually say or understand by what someone else says on a given situation. Chomsky adds that there are two structures involved in constructing a sentence namely, Deep Structure and Surface Structure. A sentence always derives from Deep Structure which exists in the mind of speakers. Then, syntactic rules will be applied to the Deep Structure. After applying the rules, Surface Structure will be obtained. The syntactic rules applied in a sentence are Movement Transformation, Deletion Transformation, and Substitution Transformation. However, the main discussion in this article is Movement Transformation. This article will elaborate some types of movement transformation in constructing English sentences.
\end{abstract}

\section{Keywords}

Movement Transformation, Deep Structure, Surface Structure

\section{INTRODUCTION}

One of the characteristics of language is that language is systematic. Here, systematic means that language is based on rules or methods. So, language is arranged with certain rules. Language does not consist of a single system; however, it consists of some sub systems such as phonology, morphology, and syntax. These sub systems are called grammar of language.

Chomsky (as cited in Radford, 1988) states that "a grammar is a model (=systematic description) of those linguistic abilities of native speakers of a language which enable them to speak and understand their language 
fluently". Chomsky (as cited in Radford, 1988) also adds that there are three inter-related theories which any detailed study of language ultimately seeks to develop namely:

a. Theory of Language Structure is concerned with the defining structural properties of natural (i.e. human) languages.

b. Theory of Language Acquisition is concerned with the question of how children acquire their native language(s).

c. Theory of Language Use is concerned with the question of how linguistic and non-linguistic knowledge interact in speech comprehension and production.

However, from the three theories above, the theory of language structure is the most important one. The reason is that if someone knows the structure of language, he/she can develop theories about how it is acquired and used.

Chomsky introduced a new concept i.e. competence and performance. Competence is the fluent native speaker's knowledge of his language; meanwhile, performance is what people actually say or understand by what someone else says on a given situation. On the other hand, competence is 'the speaker-hearer's knowledge of his language', while performance is 'the actual use of language in concrete situations' (Chomsky, 1965, p.4). Based on the concept, Chomsky introduced a new theory of grammar called Transformational Generative Grammar (TGG) or

\section{Transformational Syntax.}

TGG is a new method of sentences construction. In sentence construction, a sentence derives from Deep Structure (DS) or D-Structure which exists in the mind of speakers. Deep Structure will show the meaning intended by the speakers. Syntactic rules will be applied in the D-Structure; then, Surface Structure (SS) or S-Structure will be obtained. Deep 
Structure can be defined as the structure of a sentence which is represented in the tree diagram and phrase markers which become the input of the application of (a) syntactic rule (s), which underlies the meaning of the sentence; meanwhile, Surface Structure is the structure which is obtained from the application of (a) syntactic rule (s) to the deep structure of a sentence, which is generally used in communication.

There are three rules of transformational grammar i.e. Movement Transformation, Deletion Transformation, and Substitution Transformation. However, Movement Transformation becomes the topic of this article. The types of Movement Transformation will be applied in constructing English sentences.

\section{Movement Transformation}

All movement rules in all languages may actually be reflexes of one universal movement metarule, which Chomsky terms $\boldsymbol{\alpha}$-movement (alphamovement) (Radford, 1981). This rule says:

Move a (where alpha is a category variable, i.e. designates any

random category you care to choose). (p.203)

Ouhalla (1999) has the same opinion. He says that all movement transformations have in common the property of moving a category from one position to another in the phrase markers. This fact suggests the possibility of reducing all movement transformations to a single general process which performs all the operations previously performed by individual transformations. The general process is called Move $\alpha$, where $\alpha$ is a variable which ranges over all categories. Move $\alpha$ can be simply defined as:

Move any category anywhere 
At the first sight, the rule above seems absurd. We know that we cannot just move any constituent anywhere we like in a sentence. However, Chomsky gives a detailed explanation about the rule (as cited in Radford, 1981).

$$
\begin{aligned}
& \text { If we know that languages have rules } \\
& \text { moving constituents from one position } \\
& \text { into another in a sentence, then we } \\
& \text { ought to expect (as the simplest } \\
& \text { hypothesis) that in principle languages } \\
& \text { allow you to move any constituent } \\
& \text { anywhere, and if in practice this is not } \\
& \text { the case, then there must be a set of } \\
& \text { universal or language-specific principles } \\
& \text { which determine why it is not possible to } \\
& \text { move certain constituents into certain } \\
& \text { other positions. The task of Universal } \\
& \text { Grammar is then to discover what these } \\
& \text { conditions are that 'block' certain types } \\
& \text { of movement in language, that } \\
& \text { determine how movement rules apply, } \\
& \text { and so forth. (p.204) }
\end{aligned}
$$

Therefore, the rule of alpha-movement will be limited by a set of conditions on rule application which will specify how movement rules can, and cannot, apply. The first condition is called Structure-Preserving Constraint. The rule says:

$$
\begin{aligned}
& \text { A category can only be substituted for another category of the } \\
& \text { same type }
\end{aligned}
$$

The rule means that Noun Phrase (NP) can be moved into a Noun Phrase (NP) position, but not into a Verb Phrase (VP) position. Then, the second condition which limits the rule of alpha-movement is called Empty Node Condition. The rule says: 
A moved constituent can only be substituted for an empty category

The rule means that moved constituents can only move into empty positions (just as people can only move into empty houses). So, the rules will specify that a moved NP can only be moved into an empty NP-position, and not into an empty VP-position, or a filled NP-position, etc. For the clear description, the example of movement will be given below.

(1.a) I know what she said.
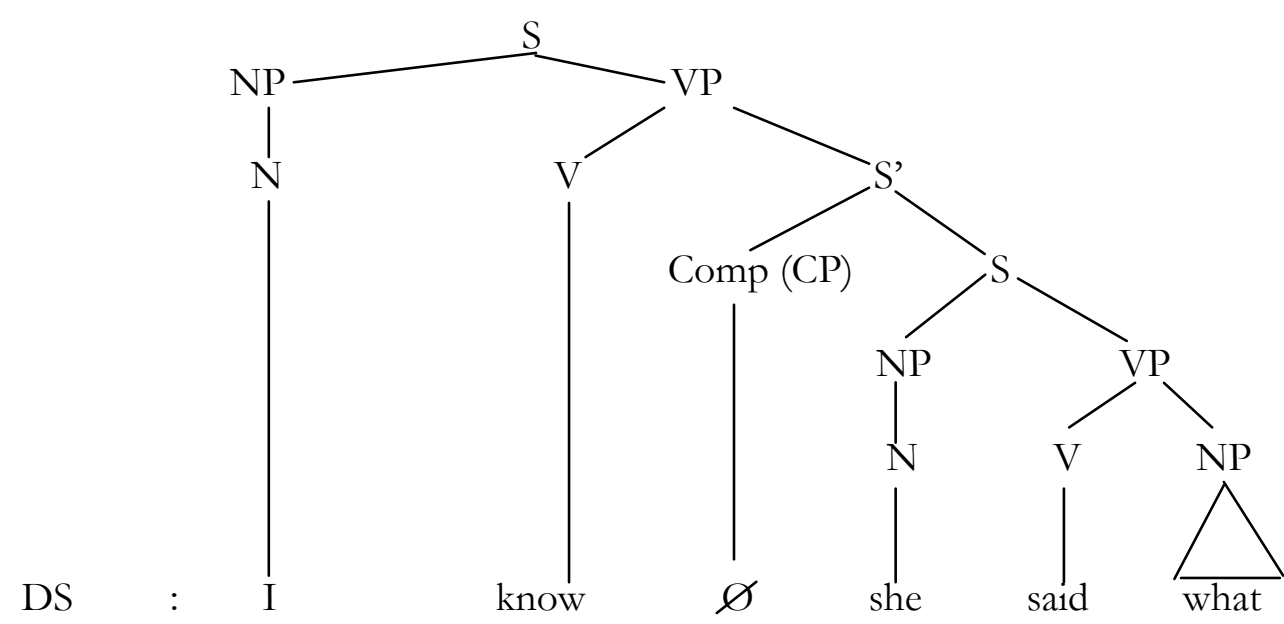

Wh-M :

SS : I know what she said.

In bracketing, the sentence (1.a) will be analysed as follows:

(1.b) I know what she said.

DS : I know [CP [IP she said what $]]$

Wh-M :

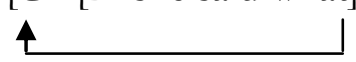

SS : I know what she said

Movement transformations in English can be classified into several types, i.e. Affix Hopping, Interrogative (Aux Movement), Wh-Movement, Passive 
Transformation, Dative Movement, Topicalisation, Particle Movement, and Relative Movement. Each type will be discussed in more detail.

\section{Affix Hopping}

Tense is an obligatory constituent of Aux. When Aux dominates a modal in addition to Tense, Tense appears on the Modal and the main verb is unmarked for Tense; it can be seen in (2.a). When Aux does not dominate a Modal, Tense appears on the main verb, as shown in (3.a) (Ouhalla, 1999).

The transformational rule that joins Tense with the verb in English is called Affix-hopping (Ouhalla, 1999). The rule says:

Move Tense (from Aux) to $V$ provided Aux does not dominate a Modal. (p.94)

Another linguist such as Lester (1971) names this rule in another term, i.e. the flip-flop rule as he says in the following:

Since the tense is generated to the left of whatever verb it will be eventually attached to, we must have some way of moving the tense marker from the left side of the verb to the right side of the verb so that it may be attached as a suffix....This particular transformational rule is used so often that it has a special nickname: the flip-flop rule. (p.53) 
(2.a) Susan will write the letter.

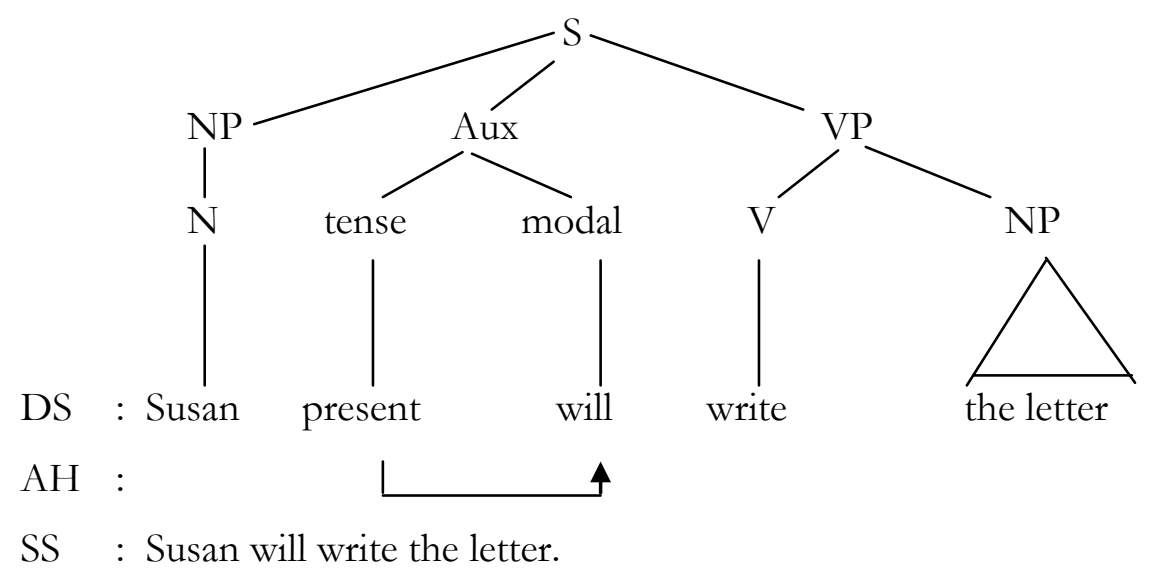

In bracketing, the sentence (2.a) will be analysed as follows:

(2.b) Susan will write the letter

DS : [S[NP Susan [Aux [present] [modal will]][VP [V write [NP the letter]]]

$\mathrm{AH}:$

SS : Susan will write the letter.

(3.a) Mary wrote the letter.

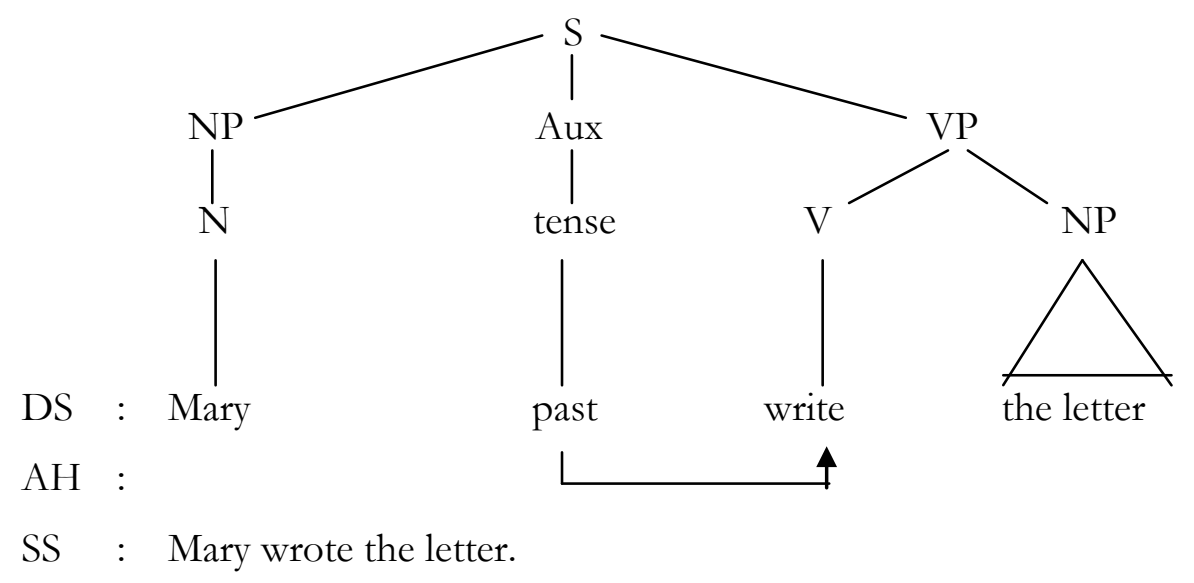

In bracketing, the sentence (3.a) will be analysed as follows: 
(3.b) Mary wrote the letter.

DS : [S [NP Mary [Aux [past] [VP [ $V$ write [NP the letter $]]]]]$

$\mathrm{AH}$ :

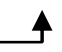

SS : Mary wrote the letter.

Lester (1971) said that the auxiliary is composed of tense, either present or past, as well as various kinds of helping verbs, which may or may not be present in any particular sentence. This grammar deals first with tense, and then with three types of helping verbs: modals, the perfect, and the progressive. Let us see the examples of Affix-hopping.

(4) She is sleeping.

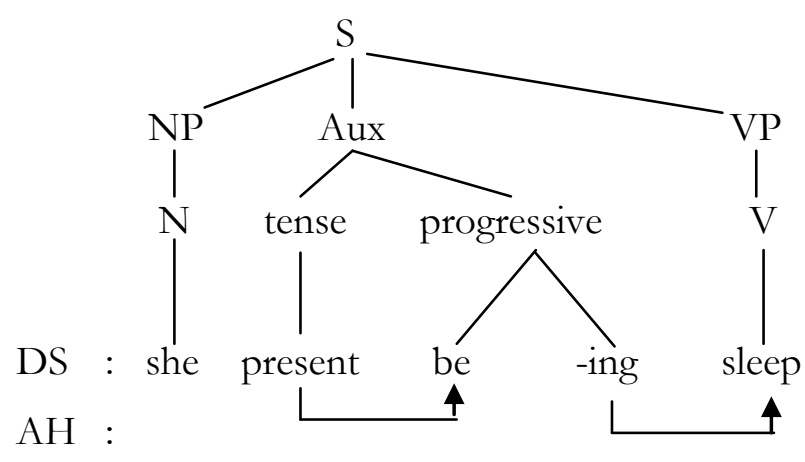

SS : She is sleeping. 
(5) He had gone.

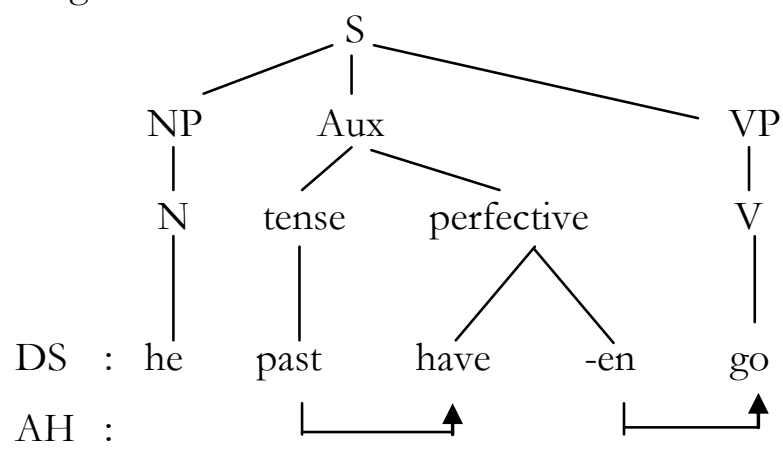

SS : He had gone.

(6) He has been sleeping.

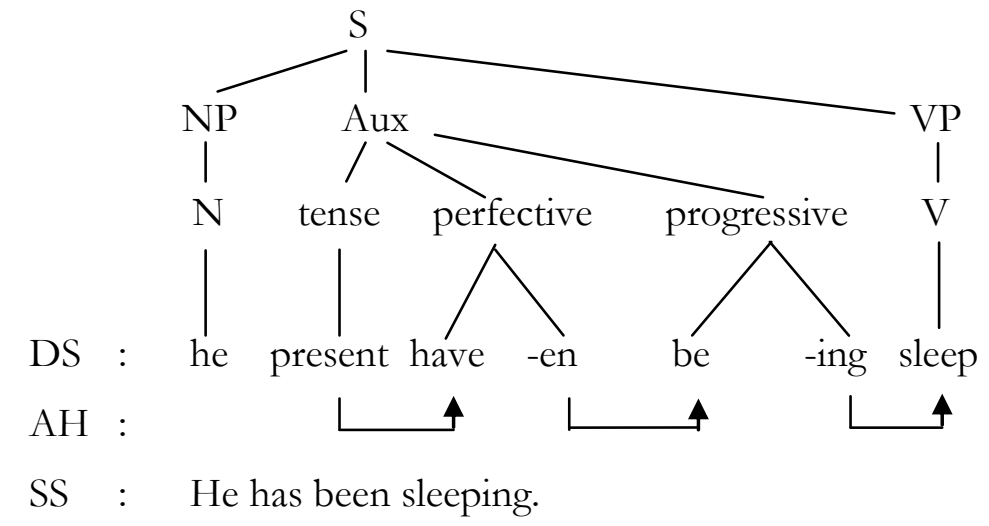


(7) They will have been going.

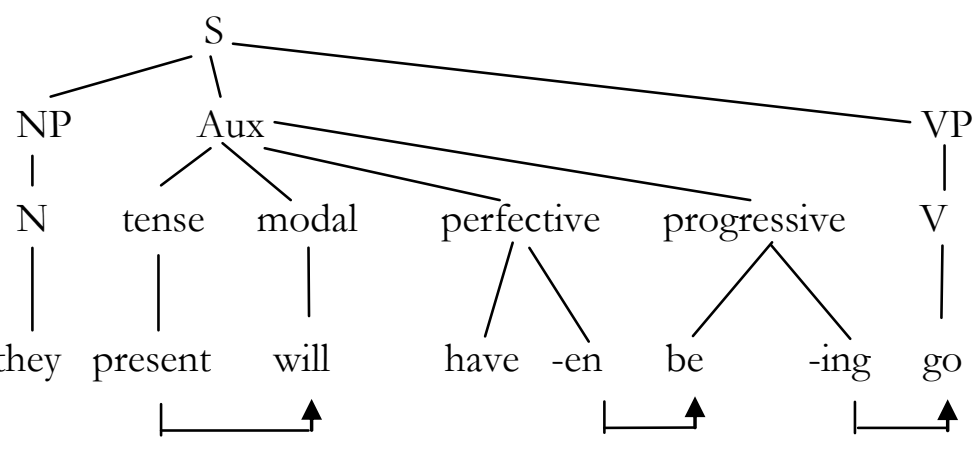

DS : they present will
$\mathrm{AH}:$
$\mathrm{SS} \quad$ : They will have been going.

This rule, affix-hopping, is compulsory. It means that Aux must move to Verb, so that we can get a grammatical sentence. If Aux does not move to Verb, the sentence becomes ungrammatical. Let us see again the example of (7). The tense marker 'present' moves to modal 'will'; if the tense marker is in the past form, so the modal 'will' becomes 'would'. The perfective marker '-en' moves to 'be' and becomes 'been', and finally the progressive marker '-ing' moves to the verb 'go' and becomes 'going'. Then, the sentence becomes grammatical.

\section{Interrogative (Aux Movement)}

The main characteristic of yes-no questions (questions which typically require 'yes' or 'no' for an answer) is that Aux and the subject appear 'inverted' compared to their order in declarative sentences. Presumably, yesno questions are derived from a DS representation where Aux is to the right of the subject seen in declarative sentences. The position in question is Comp. Comp (Complementizer) is a super constituent as it is the constituent of a super clause or sentence. The Comp of yes-no questions is marked with 
the feature $[+Q]$, and therefore requires movement to it. The rule is called Aux-raising (Aux Movement). The rule says:

Move Aux to Comp, provided Comp has the feature

specification $[+Q]$

For example:

(8.a) Can Bill solve the problem?

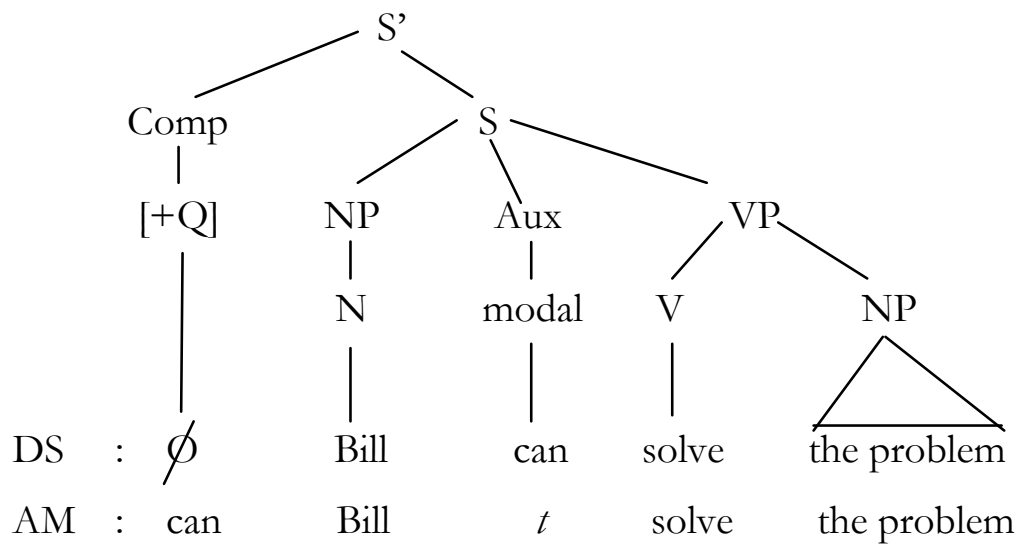

SS : Can Bill solve the problem?

(9.a) Will John fix the car?

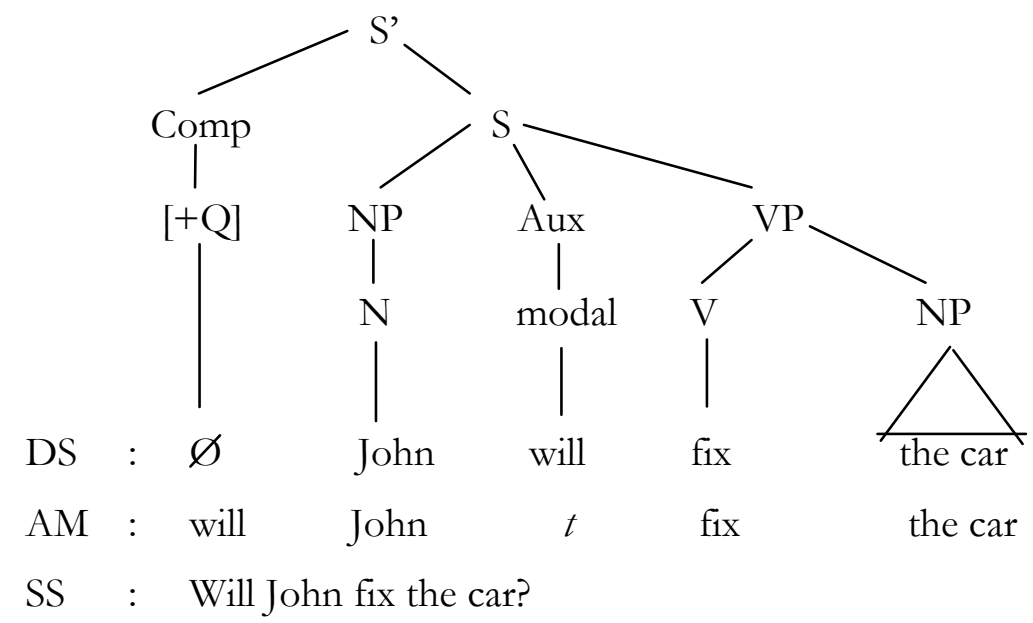


't' stands for 'Trace'. Trace is an empty category which encodes the base-position of a moved constituent. The moved element is called the antecedent of the trace (Haegeman, 1994). It is supported by Ouhalla (1999) who said that Trace designates the position from which the topicalised category is moved. Trace marks the position where the moved category is understood as far as its interpretation in the sentence is concerned. The moved category is said to be the antecedent of the trace it is related to.

In bracketing, the sentences (8.a) \& (9.a) will be analysed as follows:

(8.b) Can Bill solve the problem?

DS : $\left[S^{\prime}[+\mathrm{Q}][S[N P[N\right.$ Bill $[A u x$ can $][V P[V$ solve $[N P$ the problem $]]]]]]$ $\mathrm{AM}:\left[S^{\prime}\right.$ can $[S[N P[N$ Bill $[A u x \mathrm{t}][V P[V$ solve $[N P$ the problem $\left.]]]]]]\right]$ SS : Can Bill solve the problem?

(9.b) Will John fix the car? DS : $[S[+\mathrm{Q}][S[N P[N$ John [Aux will] $[V P[V$ fix $[N P$ the car $]]]]]]$ AM : [S will [S [NP [N John [Aux t] [VP [ $V$ fix [NP the car $]]]]]]$ SS : Will John fix the car? 
Another example of Aux-raising can be seen in the following.

(10) Did he come yesterday?

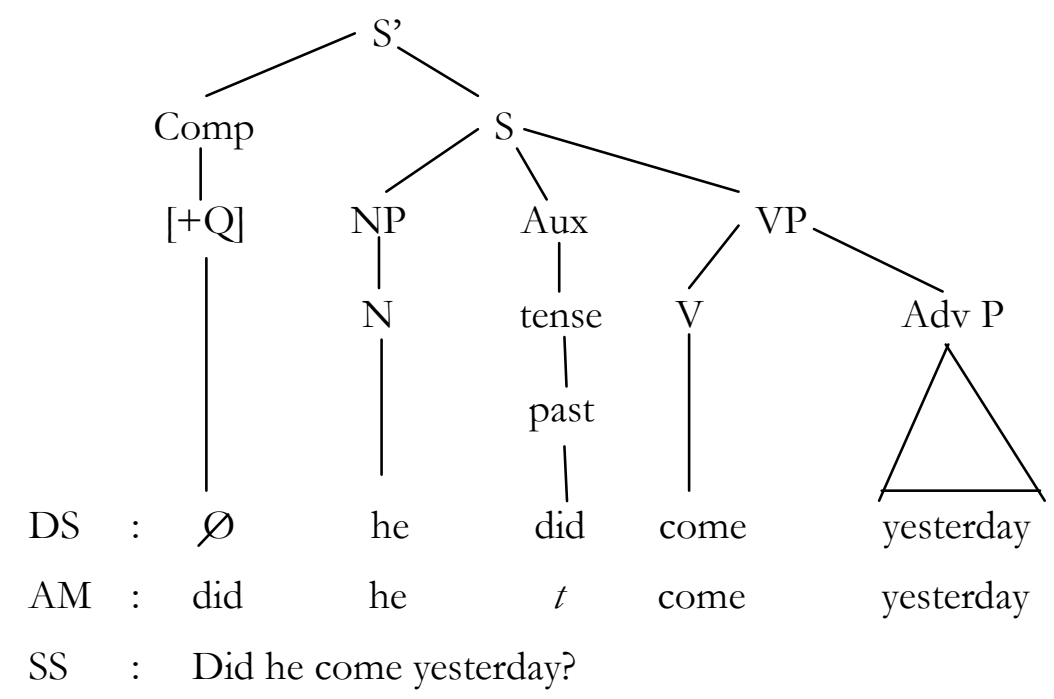

(11) Do you like this food?

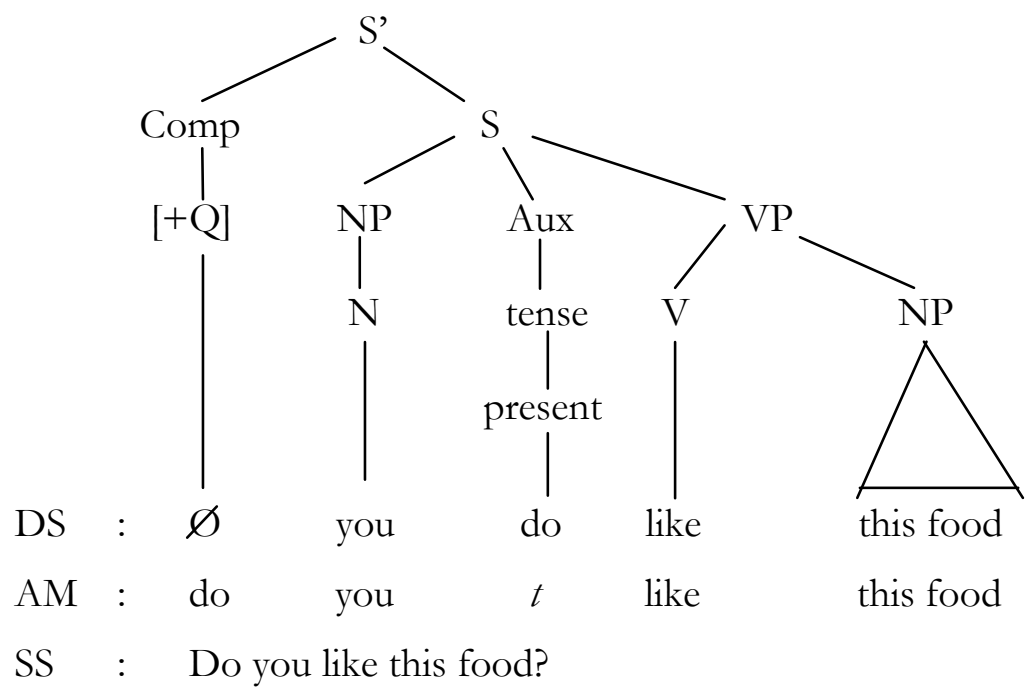


(12) Is he a journalist?

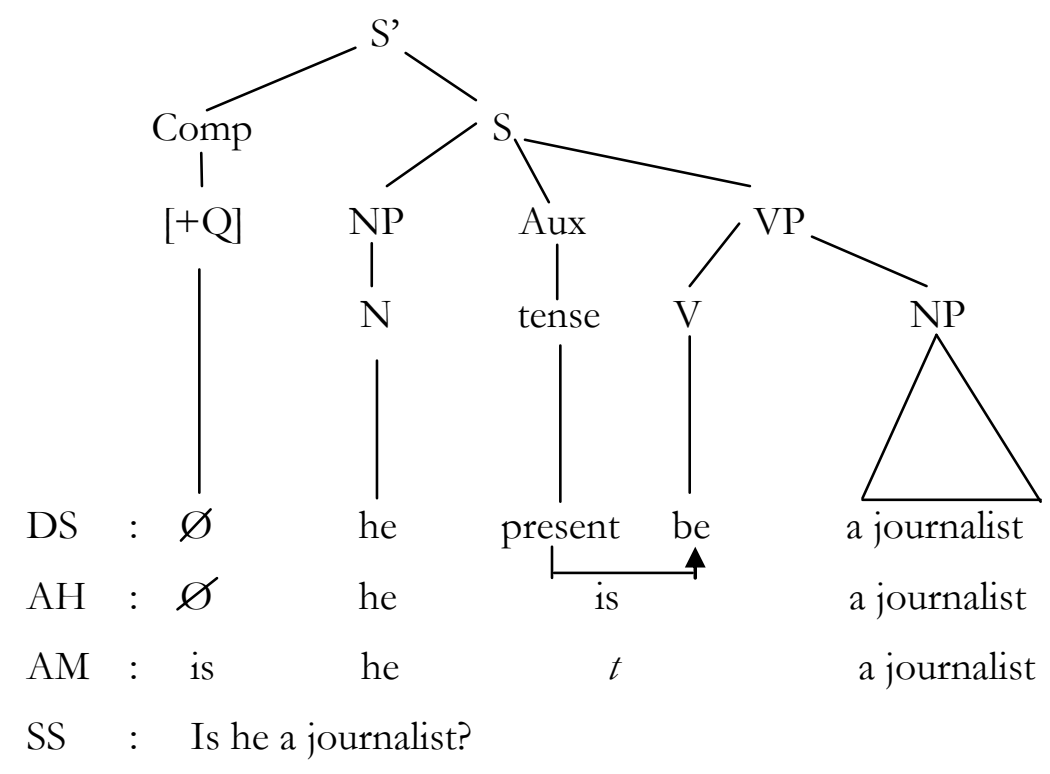

Aux-raising is compulsory. In English, if we make an interrogative sentence, the auxiliary must be moved into the initial position of a sentence. If the auxiliary does not move, the sentence becomes ungrammatical. The auxiliary 'did' moves into the initial position of the sentence as in (10); the auxiliary 'do' also moves into the initial position as in (11); and the auxiliary 'is' moves into the initial position as in (12).

\section{Wh-Movement}

The transformation responsible for movement of the wh-phrase to the sentence initial position is called Wh-Movement (Ouhalla, 1999:70). The rule says:

$$
\text { Move wh-XP to Comp }
$$


For example:

(13.a) I know what you mean.

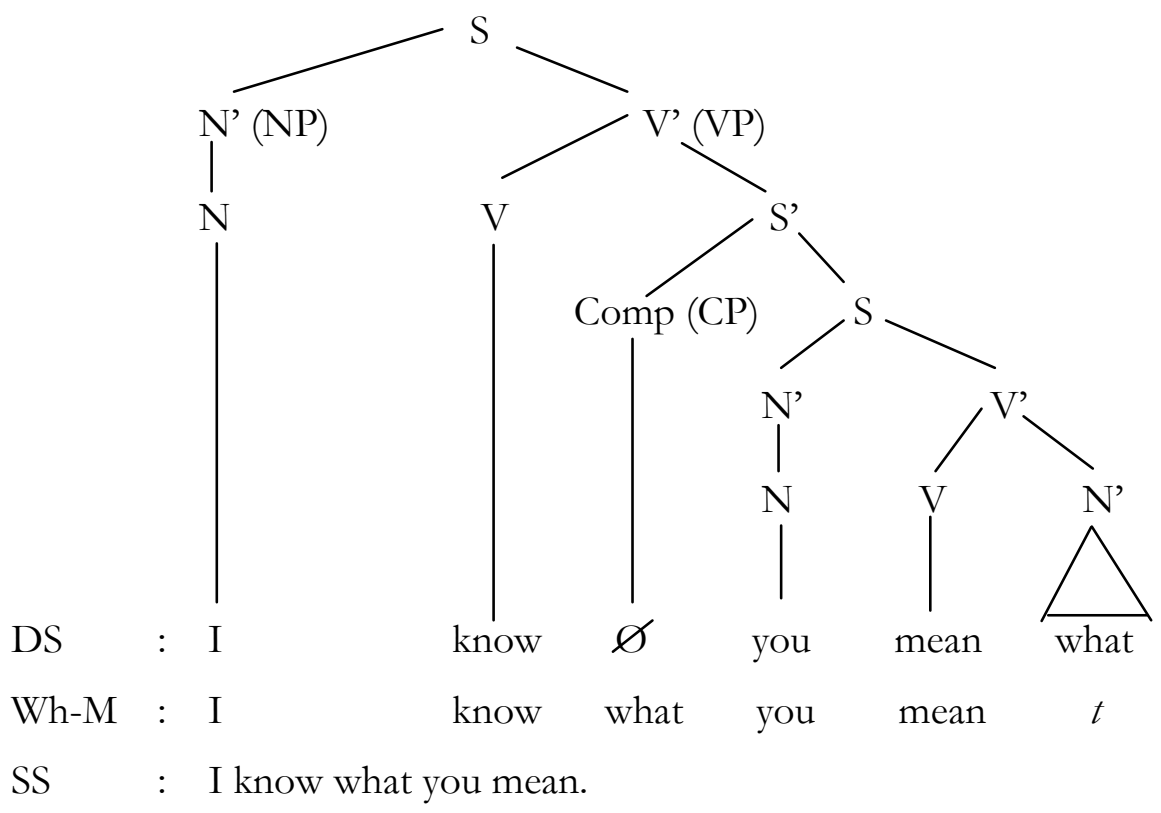

In bracketing, the sentence (13.a) will be analysed as follows:

(13.b) I know what you mean.

DS : I know [CP [IP you mean what $]]$

Wh-M : I know [CP what [IP you mean $\theta]$

SS : I know what you mean.

Wh-Movement is compulsory. It means that the rule must be applied. If we see the example of (13) above, 'what' must be moved to Comp, and the sentence becomes grammatical. The sentence 'I know you mean what' is ungrammatical in English. So, the sentence must be 'I know what you mean'. 


\section{Passive Transformation}

The passive is an optional transformational operation that converts underlying active sentences into the passive. The function of the passive is to shift the focus of attention away from the subject noun phrase and onto the object noun phrase. Sometimes the passive is employed because the subject noun phrase is unknown and irrelevant, and sometimes because the subject noun phrase is so obvious that it seems redundant to mention it (Lester, 1971).

The passive transformation can be broken down into a group of elementary transformational operations. The order in which these are presented is solely a matter of convenience, since there is no compelling evidence that indicates that the operations are relatively ordered. They are:

a. NP switch rule: the subject NP and object NP change places.

b. by-insertion rule: by is inserted between the main verb and the following NP (which was the original subject).

c. $b e-E N$ insertion rule: $b e-E N$ is inserted between the last element of the auxiliary and the main verb. 
For example:

(14.a) The glass was broken by John.

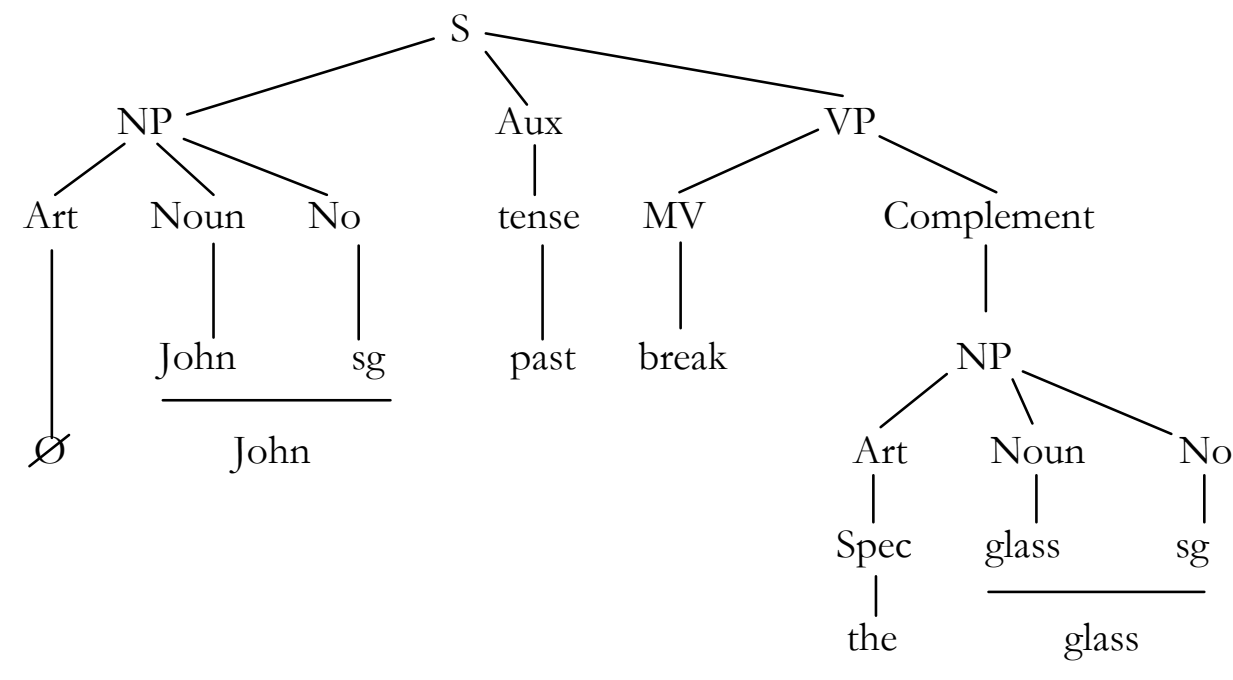

by passive

(1) NP-switch rule:

(2) by-insertion rule:

(3) be-EN insertion rule:

the glass past break John

by flip-flop rule:

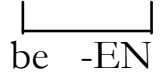

$\underset{\text { was }}{\text { be past }}$ broken 
(15.a) My camera was stolen.
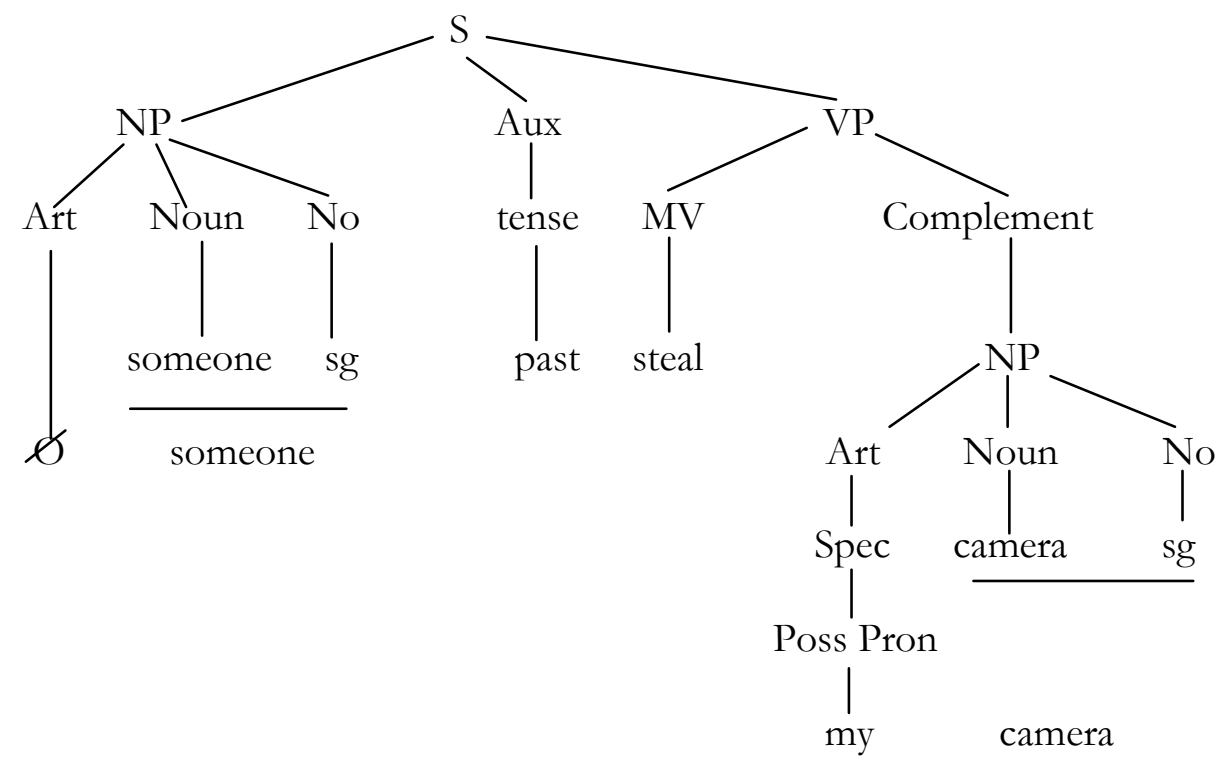

by passive

(4) NP-switch rule:

My camera past steal

(5) by-insertion rule:

(6) be-EN insertion rule:<smiles>[13CH][13CH]I</smiles>

by agent deletion rule:

$\varnothing$

by flip-flop rule:

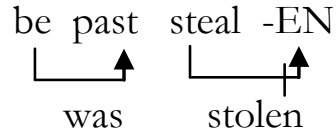

Jumino (2004) states that a passive sentence was derived from the corresponding active by applying an optional transformational rule such as:

Structural Description (SD) : NP Aux V NP

Structural Index (SI)

$\begin{array}{llll}: & 1 & 2 & 3\end{array}$

Structural Change (SC)

: $42+$ be $3+$ en by +1 
Therefore, the rule above can be simplified as follows:

(14.b) The glass was broken by John.

DS : John past break the glass

SI : $1 \quad 2 \quad 3 \quad 4$

SC : $42+$ be $3+$ en $\quad$ by +1

SS : The glass was broken by John.

(15.b) My camera was stolen.

DS : someone past steal my camera

SI $: \begin{array}{lllll} & 1 & 2 & 3 & 4\end{array}$

SC : $42+$ be $3+$ en $\quad($ by +1$)$

SS : My camera was stolen.

by +1 is put into bracket. It means that it can be omitted. In English, the agent in passive sentence can be omitted if it is in the form of pronoun (he, she, they, someone, somebody, everyone, etc). In (15.b), the subject is 'someone', so the agent (by someone) can be omitted.

Passive transformation is optional in English. It means that the rule can be applied or not. If we do not apply the passive rule, the sentence is still grammatical because a passive sentence derives from an active sentence. In (14.b), D-Structure of the sentence is 'John broke the glass. If we do not change it into passive form, the sentence is still grammatical because it is in the active form, and so do in (15.b). 


\section{Dative Movement (Dative Shift)}

Dative movement is called as Dative Shift as Ouhalla says in his book. This is the movement of NP as an object. Radford (1981) gives a simple example of dative movement (dative shift).

(16) John gave Mary presents.

DS : John gave presents to Mary

DM : John gave Mary presents

SS : John gave Mary presents.

The tree diagrams of the sentences are:

(16.a) John gave Mary presents.

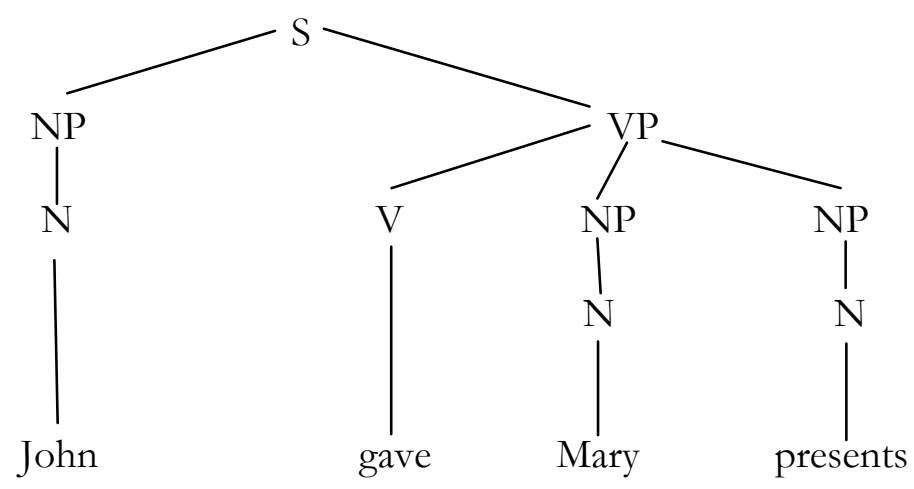


(16.b) John gave presents to Mary.

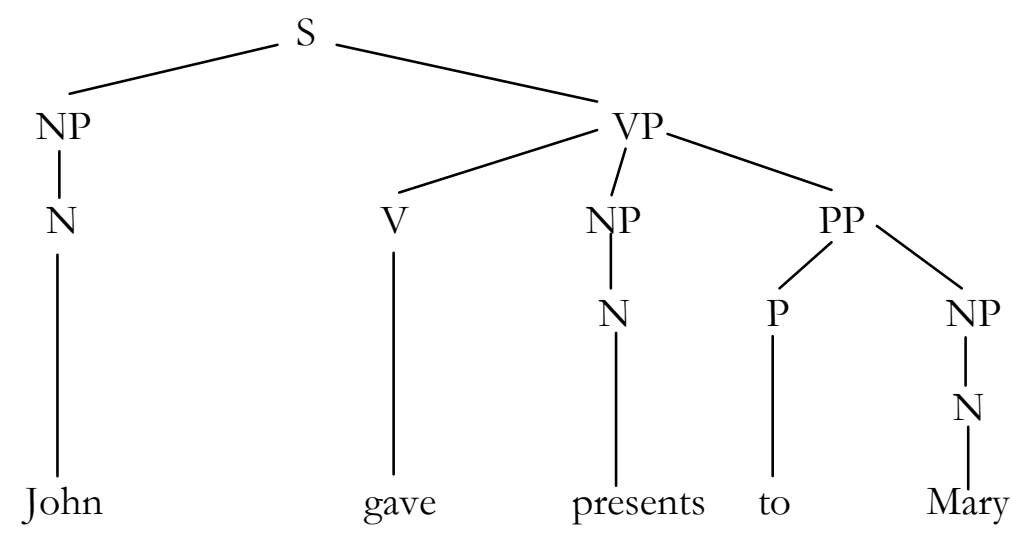

Dative shift is an optional rule. It means that the rule can be used or can be omitted. Both of the sentences, 'John gave Mary presents' and 'John gave presents to Mary', are acceptable in English. However, the sentence, 'John gave Mary presents', is always used.

\section{Topicalisation}

Topicalisation is a process of moving NP as an object into the initial position of a sentence. The NP is moved because the speaker wants to emphasize it. It is regarded as the most important message that the speaker wants to emphasize. Ouhalla (1999) gives an example of topicalisation.

(17) This problem, I can solve.

DS : $[S[N P[N$ I $]][A u x$ can $][V P[V$ solve] [NP this problem $]]]$

Top. : $[S[N P$ this problem $][N P[N$ I $][A u x$ can $][V P[V$ solve $][N P \mathrm{t}]]]$

SS : This problem, I can solve. 
The sentence can be represented in the tree diagram.

(17.a)

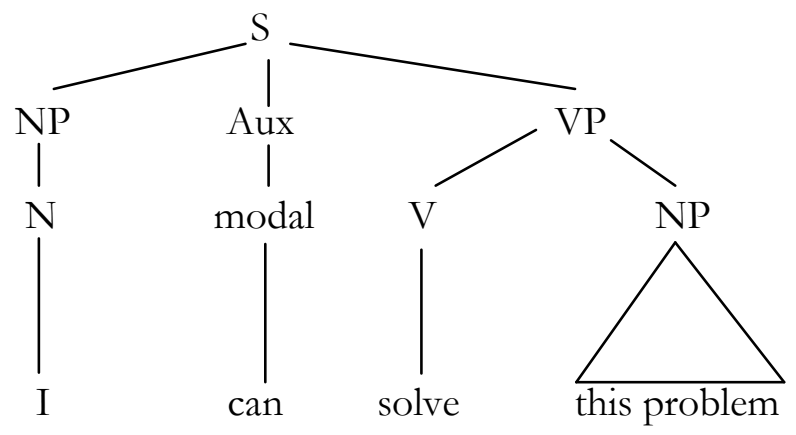

(17.b)

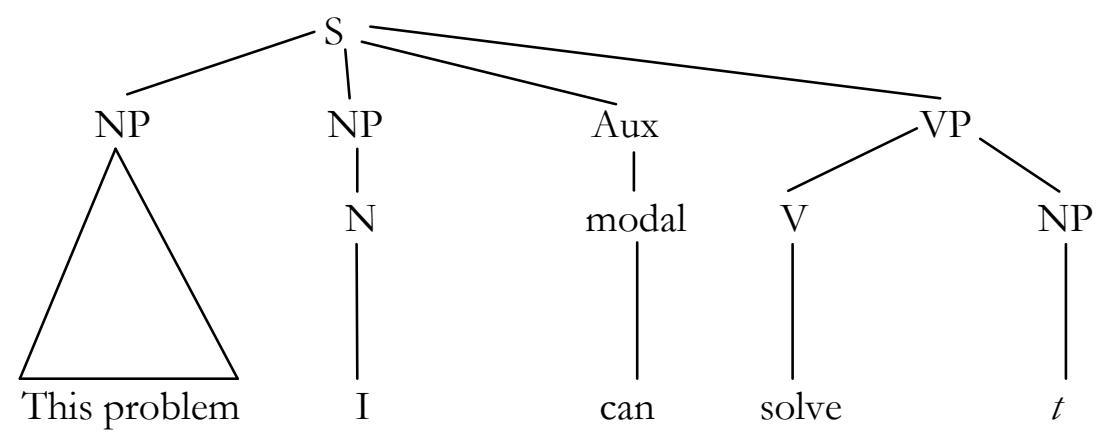

The rule of this transformation is also called topicalisation as Ouhalla (1999) says in the following:

Move XP and attach it as the leftmost constituent of S. (p.64) 
Another example of topicalisation can be seen in the following.

(18) Pizza, he likes.

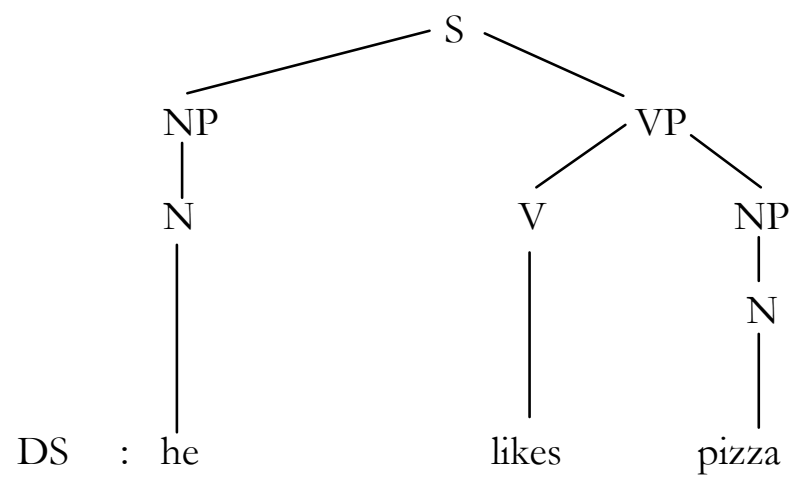

Top. : pizza he likes

SS : Pizza, he likes.

Topicalisation is optional. It means that the rule can be applied or not. Both of the sentences, 'He likes pizza' and 'Pizza, he likes' are acceptable in English.

\section{Particle Movement}

Particle movement is very unique. It means that the movement can be optional, compulsory, or even restricted based on some conditions (requirements).

a. Particle movement is optional if the object is a simple NP, for example:

(19.a) Mark sent the boy out.

DS : Mark sent out the boy

SI : $\begin{array}{lllll} & 1 & 2 & 3 & 4\end{array}$

SC : $\begin{array}{llll} & 1 & 2 & 4\end{array}$

SS : Mark sent the boy out.

If the rule is not applied in the Deep structure, 'Mary sent out the boy', the structure is still acceptable because the object is a simple 
NP. Both of the structures, deep structure and surface structure, are acceptable.

b. Particle movement is also compulsory if the object is a pronoun, for example:

(19.b) Mark sent him out.

DS : Mark sent out him

SI : $\quad \begin{array}{llll}1 & 2 & 3 & 4\end{array}$

SC : $1 \quad 1 \quad 2 \quad 4 \quad 3$

SS : Mark sent him out.

The rule must be applied in the sentence because the object is a pronoun 'him'. If the particle 'out' is not moved, the sentence becomes ungrammatical.

c. Particle movement can be restricted if the object is a heavy NP, for example:

DS : Mark sent out the boy who always makes noise in the class Part.M:

SS $\quad: *$ Mark sent the boy who always makes noise in the class out.

In the above example, if the particle 'out' is moved into the final position, the surface structure becomes unacceptable.

\section{Relative Movement}

Relative movement is a part of Wh-Movement. Relative has a role as an adjective to modify a noun. The clause which modifies a noun is called relative clause. This relative must be moved into Comp position. Comp also accommodates the constituent such as the relative, for example: 
(20) Mary will invite her old friend whom she loves.

DS : Mary will invite her old friend

Rel. : Mary will invite her old friend

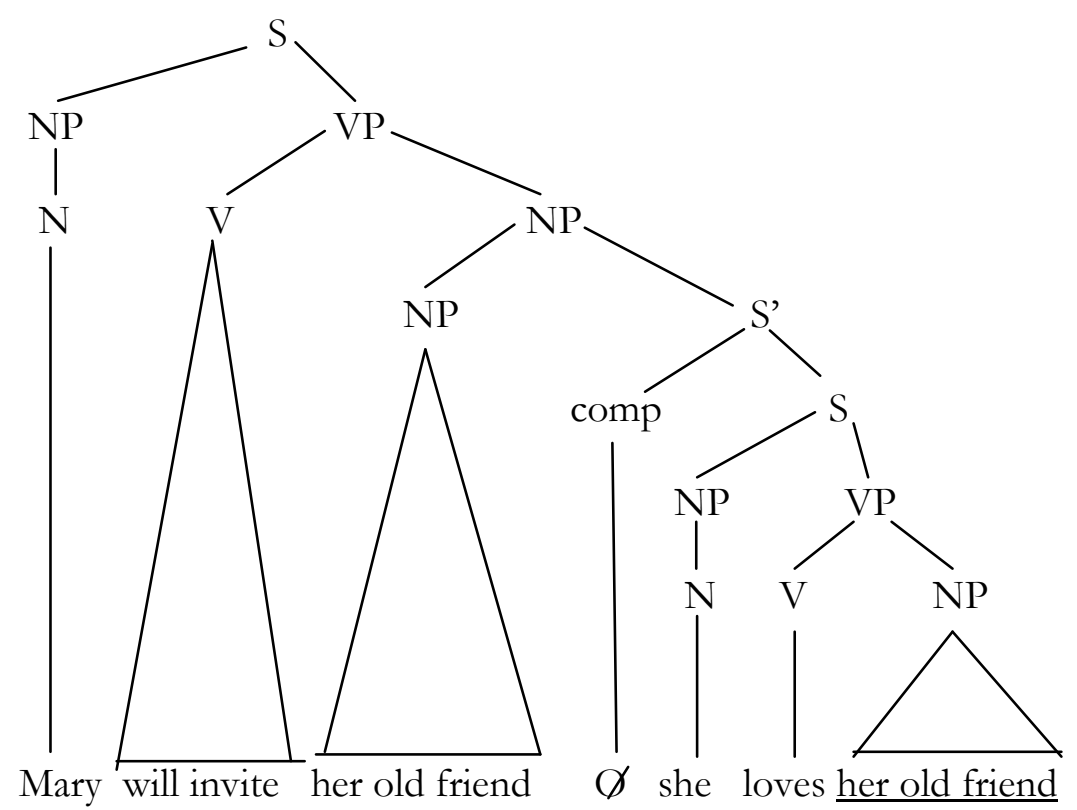

$\varnothing$ she loves whom

Rel. M : Mary will invite her old friend whom she loves $t$

SS : Mary will invite her old friend whom she loves.

'Whom she loves' is a relative clause which modifies the noun phrase 'her old friend'. In traditional grammar, it is also called an adjective clause. The wh-phrase 'whom' must move to Comp, so it becomes the relative which modifies 'her old friend' in the matrix clause. If 'whom' does not move into Comp, the sentence becomes ungrammatical. Therefore, it can be said that relative movement is compulsory in English.

However, there is a special case. Usually, the relative clause modifies the noun phrase, as its antecedent, which is the nearest to it. However, the relative clause can be put in the final position of the sentence which is not the nearest to its antecedent. Ouhalla (1999) gives an example as follows: 
(21) A man has come forward who claims to be the culprit.

DS : [ $S$ [NP a man [ $S$ ' who claims to be the culprit]] [ $V P$ has come forward]]

SS : [S [NP a man $\left.\left[S^{\prime} t_{\mathrm{x}}\right]\right][V P$ has come forward [ $S$ ' who claims to be the culprit $\left.\left.]_{x}\right]\right]$

Generally, the relative clause 'who claims to be the culprit' is put after its antecedent 'a man' as in 'A man who claims to be the culprit has come forward'. However, the relative clause can be extraposed (moved into the final position). Then, the sentence becomes 'A man has come forward who claims to be the culprit'. The transformational rule responsible for this movement is called Extraposition. The rule is formulated in the following (Ouhalla, 1999):

Move XP and attach it as the rightmost constituent of VP. (p.87)

Because this movement happen in a relative clause, so the movement is called extraposition of a relative clause. Another example of extraposition of a relative clause can be seen as follows:

(22) A book has been revised which deals with Transformational Syntax.

DS : [S [NP a book [ $S$ ' which deals with Transformational Syntax]] [VP has been revised $]]$ EXTRAPOSITION -

SS : $\left[S\left[N P\right.\right.$ a book $\left.\left[S^{\prime} t_{\mathrm{x}}\right]\right][V P$ has been revised $[S$ ' which deals with Transformational Syntax $\left.\left.]_{\mathrm{x}}\right]\right]$

As an addition, Extraposition can also move a PP or S-bar contained with an NP to the end of the S containing it. For example, see the sentences (23) and (24) below. 
(23) A critical review has just appeared of my latest novel.

DS : [S [NP a critical review [PP of my latest novel]] [VP has just appeared EXTRAPOSITION

SS : [S [NP a critical review [PP $\left.\left.\mathrm{t}_{\mathrm{x}}\right]\right][V P$ has just appeared [PP of my latest novel] $\left.]_{\mathrm{x}}\right]$

(24) A news has been known that he is ill.

DS : [ $S$ [NP a news [ $S$ 'that he is ill]] [VP has been known

L EXTRAPOSITION

SS : [S [NP a news [ $\left.\left.S^{\prime} \mathrm{t}_{\mathrm{x}}\right]\right]\left[V P\right.$ has been known $\left.\left.\left[S^{\prime} \text { that he is ill }\right]_{\mathrm{x}}\right]\right]$

\section{Conclusion}

Transformational Grammar is a method of grammar proposed by Noam Chomsky. The method derives from Chomsky's new concept i.e. competence (the speaker-hearer's knowledge of his language) and performance (the actual use of language in concrete situations). A sentence consists of two structures i.e. Deep Structure and Surface Structure. DStructure will show the meaning intended by the speakers. Then syntactic rules will be applied to the D-Structure. After applying the rules, Surface Structure will be obtained. One of the syntactic rules applied in D-Structure is Movement Transformation. Movement Transformations in English sentence construction are Affix Hopping, Interrogative (Aux Movement), Wh-Movement, Passive Transformation, Dative Movement, Topicalisation, Particle Movement, and Relative Movement. 


\section{REFERENCES}

Abedi, F., Moinzadeh, A., \& Gharaei, Z. (2012). Wh-movement in english and persian within the framework of government and binding theory. in International Journal of Linguistics,4(3). Retrieved from http://www.macrothink.org/

Akmajian, A., \& Heny, F. (1975). An introduction to the principles of transformational syntax. Cambridge, Massachusetts: M.I.T. Press.

Arifin, E. Z., \& Tasai, S. A. (2000). Cermat berbahasa Indonesia. Jakarta: Akademika Pressindo.

Bach, E. (1964). An introduction to transformational grammars. New York: Holt, Rinehart and Winston, Ltd.

Brown, E. K., \& Miller, J. E. (1982). Syntax: Generative grammar. London: Hutchin Son \& Co. Ltd.

Chaer, A. (2006). Tata bahasa praktis bahasa Indonesia. Jakarta: PT. Rineka Cipta.

Chomsky, N. (1957). Syntactic structures. The Hague: Mouton Publishers.

Chomsky, N. (1965). Aspects of the theory of syntax. Cambridge, Massachussetts: M.I.T. Press.

Chomsky, N. (1977). On Wh-Movement. In P. Culicover, Formal Syntax (pp. 73-132). New York: Academic Press.

Chomsky, N. (1981). Lectures on government \& binding. Dordrecht: Foris Publications.

Chomsky, N. (1995). The minimalist program. Cambridge, MA: M.I.T. Press.

Culicover, P. W. (1997). Principles and parameters: An introduction to syntactic theory. Oxford: Oxford University Press.

Fowler, R. (1971). An introduction to transformational syntax. London: Routledge and Kegan Paul Ltd. 
Grinder, J. T., \& Elgin, S. H. (1973). Guide to transformational grammar: History, theory and practice. New York: Holt Rinehart and Winston Ltd.

Haegeman, L. (1994). Introduction to government \& binding theory. Oxford: Blackwell.

Harman, G. H. (1963). Generative grammars without transfromational rules: A defense of phrase structure. Language,39(4), 597-616. New York: Linguistic Society of America.

Harrocks, G. (1987). Generative grammar. New York: Longman.

Jacobsen, B. (1977). Transformational generative grammar. Amsterdam: North Holland Publishing Company.

Johnson, K. (2004). Introduction to transformational grammar. Massachusetts: University of Massachusetts.

Lester, M. (1971). Introductory transformational grammar of English. New York: Holt, Rinehart and Winston, Inc.

Ouhalla, J. (1999). Introducing transformational grammar (2nd ed.). New York: Oxford University Press.

Radford, A. (1981). Transformational syntax. London: Cambridge University Press.

Radford, A. (1988). Transformational grammar: A first course. London: Cambridge University Press.

Radford, A. (1997). Syntax: A minimalist introduction. New York: Cambridge University Press.

Radford, A. (2009). Analysing english sentences: A minimalist approach. New York: Cambridge University Press.

Saragih, A. (2003). Finit ada dalam bahasa Melayu pantai timur Sumatera Utara. Julisa,3(1). Medan: Faculty of Literature UISU Medan.

Suhadi, J. (2004). The adequacy of empty category in the theory of syntax. Julisa, 4(2). Medan: Faculty of Literature UISU Medan. 
Wang, Q. (2010). Drawing tree diagrams: Problems and suggestions. Journal of Language Teaching and Research,1(6), 926-934. Finland: Academy Publisher. 